\title{
New Strategies in Library Services Organization: Consortia University Libraries in Spain
}

New political, economic, and technological developments, as well as the growth of information markets, in Spain have created a foundation for the creation of library consortia. The author describes the process by which different regions in Spain have organized university library consortia.

$\infty$ panish libraries are public entities that depend either on central or local governments and are funded through either the national general budget or the regional government (Comunidades Autonomas) budget. On one hand, the player at the national level is the Education and Culture Ministry, which contributes to the fifty-two state public libraries and shares jurisdiction with the regional government. On the other hand, universities are self-governed institutions of a public nature regulated by the Ley de Reforma Universitaria, or University Reform Law, which was approved by the Spanish parliament in 1983 to promote scientific study and greater selfgovernment of Spanish universities. Universities have their own budget, and they are mainly funded by the regional government. The university library system is currently made of about fifty public libraries and twelve private libraries.

Since the second half of the 1980s, a new philosophy concerning public services has spread in Spain, as in other European countries: a philosophy calling for higher quality and more efficiency in the management and administration of the public capital. There has also arisen a claim to the government's satisfactory use of public funds as a social right, as well as a claim to a return on that capital in social terms. This is where libraries' public services come into play.

There is a clear interest in all the aspects related to the introduction of new techniques in management. Quality management, effectiveness and efficiency measuring, costs control, services assessment, and users content or analysis from the stakeholders' point of view are concepts that emerge in university libraries. In order to adjust to the circumstances, universities are changing their management procedures, and university libraries have been forced into managing their "business" according to managerial criteria.

The commonality of their activities, and the relaxation of geographical boundaries fostered by information technologies, have encouraged libraries to join consortia in order to remain relevant in the current library services context. Such concepts as the "electronic," "digital," and

Miguel Duarte Barrionuevo is head Director of the Central Library of the University of Cadiz (Andalucia), and an active contributor of the University Libraries Consortium of Andalucia. "virtual" libraries lead, from my point of view, to a different configuration in the library services context; they have pushed the library managers to consider strategically where they are and what is their most adequate position within this new configuration. Departments dealing with information are to be wider, more heterogeneous, and multidisciplinary. New organization strategies need to be defined in order to offer services in a different way

When library managers are forced to obtain the best results out of their limited resources, the organization of consortia represents a qualitative leap forward in cooperation, efficiency, and cost-savings. Library consortia aim to share resources and to promote participation on the basis of the mutual benefit of the libraries involved and, although the concepts of cooperation, coordination, and sharing resources are not new in the library world, the organization of library consortia introduces a major level of commitment and involvement among the participants.

\section{New Settings, New Facts}

Libraries are going through a crisis. A library is still an institution with a strong traditional character, but its traditional duties as depository of knowledge no longer justify its costs, and the crisis is exacerbated by an accelerated technological and informative revolution. ${ }^{1}$

Within the changing atmosphere of the Spanish university in the last few years, goals and objectives are affected by a number of socioeconomic, institutional, and technological factors, as well as others with an internal character that push these institutions to move toward change as an opportunity to maintain continuous improvement. Materials and services are more expensive, and technology is more sophisticated every day, which leads to a need for strong investments. The public financing funds are more and more limited while the costs are growing. The university, in general, is suffering from a lack of efficiency and organizational flexibility; staff rejects monotonous tasks and holds high expectations; the fast dynamics of the implementation of information technology in the last few years has caused a very serious imbalance in the skill levels of people and in job-position demands.

All these factors generate a new setting of weaknesses and hopes to which the university libraries have to respond in order to maintain their competitive advantages.

\section{Technology}

Technology has recently become a strategic element in the development of libraries. Technology is more and more sophisticated and its life is shorter. Its use implies 
the need of strong investments in computer and communication infrastructure.

\section{Economical Pressure on Information Market Agents}

Materials costs have diversified and are more and more costly, with annual growths far exceeding even inflation rate levels. An absolute change has been produced in the supply and demand of the information market, which causes the agent's utter disorientation: the publishing sector is adapting very slowly to the electronic context; the distribution sector needs a deep technological and organizational transformation (few Spanish suppliers offer added value services such as cataloguing, outsourcing, or material preparation-Puvill Libros, or filial multinationals such as Blackwell or Dawson are exceptions). Electronic Data Interchange, a European standard like SISAC, is not a standard format among the sector and there is not a national supplier that offers services of the Approval Plans type.

Additionally, the agents of the information market are very conditioned by the change of the demand orientation. Specialized users (teachers, researchers, thesis students, etc.) demand from libraries electronic resources, quick information, and access at all times from remote locations.

This conflicts with the restrictive tendencies in the maintenance of the public services and drastic budget cuts. Libraries are forced to obtain the highest possible ratio of efficiency in the use of the fewest resources.

\section{Total Quality Management Implementation and Other Management Techniques}

The result is implementation of Total Quality Management (TQM), which guarantees quality of services. It is important to consider TQM as an instrument that develops organizational strategies. It is a continuous process developed in order to replace obsolete types of organization, to orient the corporate activity as a permanent basis to the processing optimization, and to obtain a coherent relation between the efficacy in the reaching of objectives and the efficiency in the use of resources.

Changes in the editorial industry, the budget cuts, the quick expansion of electronic resources, the new price politics, and the problems related to copyright and intellectual property form the new setting. In this context, the consortia organization is considered by the university and library managers as a means to face the challenges which the new settings imply, to unify their pressure capacity with regard to the different agents, and to take advantage of the system's strength in order to adjust to the new situation and improve their competitive advantage.

\section{Adequate Information Technologies}

The Spanish university libraries are connected to the academic information network upheld by RedIris, a scientific-technical installation that depends on the Science and Technology Office of the Prime Minister.

The main line that maintains the RedIris services is formed by seventeen nodes in each region (Comunidad Autónoma), connected by ATM circuits on ATM accesses of 34/155 Mbps. Each node is formed by a set of communication equipment that allows the coordination of the main transmission means and of the access lines from the centers of each regions.

RedIris participates in the TEN-34 Project, which aims at building up an IP Paneuropean net of $34 \mathrm{Mbps}$, that interconnects us with the different academic and research nets and that is planned to become a TEN-135 in 1999. ${ }^{2}$

On the other hand, the region (Comunidad Autónoma) incorporates added value elements to the Net segments they manage, such as faster access speeds that allow centralized architecture (for instance, Union Catalogue Consortia Libraries of Galicia is managed through a broad band net of $155 \mathrm{Mbps}$ ). The region also allows access to databases in CD-ROM and electronic formats orientated to the final users in a regional context. For instance, the Scientific Computer Center of Andalucía manages twenty-two databases in CD-ROM and other electronic formats that can be searched by all the Andalusian universities and research centers through the Andalusian Scientific Research Net.

\section{Homogeneous Automation Level}

The automation process of the library services, initiated at the end of the decade of the ' 80 s, is practically completed. Dobys-Libis, Libertas, VTLS, Absys, and Sabini are the most widely used library management systems. ${ }^{3}$ Since 1997 some libraries have updated their library automation system to Unicorn (Sirsi) and Innopac (Innovative Interfaces).

The Spanish university libraries have a homogeneous automation level and can establish projects from the consortia perspective, such as regional union catalogs, sharing electronic information resources, and shared purchase policies.

\section{Favourable Political Situation}

Traditionally, the cooperative efforts have obtained little offical support. However, in the last years, a positive attitude can be perceived from the academic authorities in 
relation to cooperation activities and the cooperative projects development, both as an answer to the need to reduce costs by sharing resources and as a means to face the growing and unstoppable demand from the users.

The initiatives for the consortia organization are supported by highest academic level institutional agreements among the universities: principals and vice-principals of research (such is the case of the Consortia of Andalucia and Madrid) or they are the result of initiatives taken by the autonomous government (Galicia Consortium) or a confluence of interests between the autonomous government and the universities (Cataluña Consortium).

\section{Remote Access to End Users' Information Resources}

Following the automation projects and the network technologies and data transmission development, most university libraries have made projects for all information resources integration and maintain a wide group of services: campuswide networks, catalogs, databases in CDROM (e.g., Indice Español de Ciencias Sociales y Humanidades, Indice Español de Ciencia y tecnología, Aranzadi Legislación y Jurisprudencia, Medline, ABI Inform, Academic Search), e-mail, and remote access via Internet. Access to all resources is available through the libraries management system Opac Web. There is access to any of these resources from any point connected to the network, whether from terminal servers, workstations, PCs, Unix stations, or MACs.

\section{Cooperation in Spain}

Up to the middle of the " 80 s, university libraries were separate realities with scattered funds and disorganized services; they were not structured as a system and they were lacking any tradition or mentality of cooperation. In a 1994 poll, only 40 percent of university library directors declared that cooperation among libraries was important. ${ }^{4}$

We could say that the cooperation initiatives depend on the will of the people who obtain little support from the government. Therefore, two different stages could be set: one in which cooperation is the result of personal actions, taken with no institutional support, in which local projects are undertaken; or one in which individual initiatives are taken by the people in charge of libraries and a certain concern from the central government converge.

\section{Will to Share Resources}

Spain did not join the movement toward library automation until the '80s. At this time, the cooperative tenden- cies now associated with information and communication technologies were only slightly realized in the libraries. Eventually, however, a consolidation of efforts took place, helping to bring about, at the end of the ' $80 \mathrm{~s}$ and beginning of the ' 90 s, some important cooperative initiatives out of which some specialized union catalogs could be brought.

Some of the first cooperative initiatives arose from the Association of Specialized Libraries. ${ }^{5}$ Among these we can point out the Coordinating Committee of Biomedical Documentation, whose mission was to promote the cooperation and rationalization of document resources in the field of biomedicine. This committee holds conferences and maintains a union catalog of the daily publications on health services accessible through Internet. ${ }^{6}$ Documat, created in 1988, groups together the libraries specializing in mathematics and maintains a union catalog of journals on which basis are organized plans of shared acquisition. MECANO groups together the libraries of the schools of engineering and maintains a union catalog accessible through Internet?

Early cooperative initiatives were also promoted by the Library Automation Systems Users Groups. Red Universitaria Española de Dobis/Libis began in 1990 when twelve universities using the system decide to create an online union catalog maintained by the University of Oviedo. The Libertas Spanish Users Group maintains its union catalog associated with SLS Database, accessible online from Bristol. RUECA is the union catalog of Absys users. ${ }^{8}$

\section{Need to Cooperate}

In the early ' 80 s a forum started in universities that attempted to influence the writing of the University Statutes (as a result of the Ley de Reforma Universitaria) and establish a general criterion for regulations.

As a result of this debate, two documents have been published and have proved to be essential for subsequent cooperative development. ${ }^{9}$ Some reports from conferences on university libraries held in 1989 in the University Complutense of Madrid had a wide influence at the national level, and the same year, FUNDESCO produced a report about the state-of-the-art in automation in the Spanish university libraries. ${ }^{10}$

The situation that is repeated in these reports about the libraries is extremely pessimistic. Their evolution from 1985 to 1995 has been perfectly described by M. Taladriz and L. Anglada as "the lack of recognition of the role of university libraries ... the dispersion of bibliographical funds ... the general disorganization of the library services. ..."11

In 1988, Red de Bibliotecas Universitarias (REBIUN, University Libraries Network) was created. Although ini- 
tially only nine university libraries were involved, the number grew to seventeen during the following years. The cooperative activities were centralized, and they obtained remarkable results in training, the improvement of library interlending, and in the publishing on CD-ROM of bibliographical records from participant libraries.

At the same time, and thanks to the celebration of the IFLA Congress in Barcelona in 1993, the general need to create a wider discussion forum including all the university libraries and to obtain better cooperation and coordination was established.

This idea crystallized with the creation of the Conferencia de Directores de Bibliotecas Universitarias y Científicas (COBIDUCE, the Conference of University and Scientific Libraries Directors). The first working meeting was held in November 1993. ${ }^{12}$ This led to the merging of REBIUN with COBIDUCE in order to concentrate all the cooperation efforts into a single institution. A single institution, which kept the name of REBIUN, was created in 1996. In 1998, REBIUN became the local committee of the Conferencia de Rectores de las Universidades Españolas (CRUE, Conference of Spanish University Principals). REBIUN has become the organization that oversees all the cooperation and coordination efforts in Spanish academic libraries.

REBIUN activities include a union catalog published on CD-ROM, "Regulations for University and Scientific Libraries," agreements on interlibrary loans, and activities in different working groups. ${ }^{13}$

\section{University Libraries' Consortia}

In the past few years the transfer of powers to the autonomous regions on education and culture, a consequence of a constitutional order, has brought about another political and administrative context for the achievement of the libraries' objectives.

The autonomous regions are now working on the design of regional development plans or regional information systems that are related, unfailingly, to the cooperative activity of the libraries of the territory.

This initiative can be applied to university libraries as well as any other type of library, which, through their institutions, request their autonomous governments' assistance or funding in order to achieve cooperative projects. Or it could be done the other way round: a government can outline an action plan for its libraries and suggest it to the potential participants.

Thus, the basis for consortia development was set in the second half of the ' 90 s, and encouraged by events like the celebrated conference in Cádiz, organized by the University of Carlos III de Madrid and the University of
Cádiz libraries, and Ebsco Information Services (Spanish branch) in 1998.

\section{Catalonia Consortium of University Libraries (Consorcio de Bibliotecas Universitarias de Cataluña)}

We could sum up the situation in Catalonia according to the following: the existence of new automated libraries, few automated records, the use of their own automation systems, and the existence of only three universities. We can establish some cooperation background developed at this time: CRUC, CAPS, and the joint selection of an automation system realized by Universidad Autónoma de Barcelona and Universidad Politécnica de Cataluña.

It is not until the " 90 s that positive factors combined to move the cooperative movement a step forward in Catalonia. These positive factors were a homogeneous state of automation among university libraries, a good communications network, and the use of standards for library data recording. The previous cooperative movements and an analysis of the worldwide evolution of libraries helped in the building of a united view in which cooperation appeared as an additional instrument for the improvement of the library world.

The university library directors of Catalonia considered cooperation a way to accelerate the evolution of libraries, to create new services, to facilitate changes, and to save expenses. With this conviction, they wrote a proproposal for the creation of a library network in Catalonia, which in 1993 resulted in the interconnection of the university libraries in Catalonia, followed in 1995 with the first steps toward the creation of the United Catalog of the Universities of Catalonia. This catalog was fully operative in early 1996.

At the end of 1996 the University Library Consortium of Catalonia (CBUC) was created with the task of improving library services through cooperation. ${ }^{14}$ Its objectives are:

- To create new working tools

- To improve services

- To build a digital library

- To take better advantages of resources

- To face together the changing role in libraries

The CBUC comprises the University of Barcelona, Universidad Autonoma de Barcelona, the Politechnical University of Catalonia, Pompeu Fabra University, the University of Girona, the University of Lleida, Rovira i Virgili University, the University Oberta of Catalonia, and the Library of Catalonia. The direction of CBUC is determined by a board of representatives from each of the institutions, an executive committee of six members, and a technical committee of library directors. A staff of seven 
runs the CBUC office, and different working groups audit active plans and study possible issues of concern.

\section{University Libraries Consortium of the Madrid Region (Comunidad Autonoma de Madrid)}

The Public University Libraries, based in the Madrid region (Universidad de Alcalá, Universidad Carlos III, Universidad Complutense, Universidad Politecnica, Universidad Rey Juan Carlos, and Uiversidad Nacional de Educación a Distancia), are developing many cooperation programs with the following objectives:

- To facilitate access to information resources

- To improve the existing library services

- To test and promote the use of information and communication technologies

- To reduce costs by sharing resources ${ }^{15}$

Two programs have already been initiated:

Interlibrary loan. An agreement to obtain a faster delivery system for books and journal articles has been established. Using the services of a private courier company, maximum delivery time from one university to another will be set to forty-eight hours. This service started working on the first of Sepember.

Training. Different courses for the joint training of library staff are being organized on a cooperative basis.

In the future, other programs will be developed, including a union catalog (with the creation of a collective data basis that will also save cataloging costs by sharing bibliographical resources); and an elecronic library, which will allow common access to electronic resources.

\section{Galician Libraries Consortium}

The Galician Libraries Consortium is the result of a regional government intiative. ${ }^{16}$ In November 1996 the Xunta de Galicia signed an agreement of scientific and technological collaboration with Fijitsu ICL Spain in which the company agreed to develop the telecommunications infrastructure of the community: the Galician Information Highway (AGI: Autopista Gallega de la Información). Inaugurated in 1997, AGI serves as the basis for projects with great political and social appeal. Three projects were embarked upon:

- tele-teaching,

- tele-medicine, and

- access to libraries

Users have access to a loan service by which a loan may be requested from any library in the consortium. The loan works as it would work in a local climate, with the same limitations, controls, and blocking of any other local loan system. The request to the system is sent online and is fulfilled within twenty-four to forty-eight hours.

The consortium originally was to encompass all types of libraries, but as the project advanced, it was decided to restrict the collaboration to university libraries. This allowed the project to move forward with greater speed, because the member libraries had more narrowly defined interests and concerns.

The Xunta de Galicia prepared the "Protocol of Intentions," which has been signed by the highest representatives of the three Gallician universities (Universidad de Santiago, Universidad de la Coruña, and Universidad de Vigo). This protocol is characterized by two essential ideas:

1. Allow adequate time for planning individual incorporation into the consortium, so that each institution may participate at the rate it deems appropriate.

2. Create a permanent working commission formed by representatives of the institutions involved, which will:

- answer existing and future questions;

- define the model of consortium that each organization desires to establish through specific objectives; and

- promote adequate measurement in order to obtain the objectives that have been designed.

\section{Andalucian University Libraries Consortium}

In the era of the Internet, electronic documents, and the virtual library, maintaining independent libraries is out of order. In addition, the efforts needed to face the challenges of the information society and the changes that society is demanding of universities are destined to become weaknesses more than strengths in those institutions that face them individually.

There are many reasons why it is advisable for libraries to approach these challenges collaboratively:

- The productivity and competitiveness that society demands of the universities

- The huge technological opportunities to share information

- The importance of the changes that are taking place in the products and services that the information market offers

- The high cost of the new products (e.g., e-journals)

- The need of very specialized knowledge in order to activate some of these services

- The growing demands of library users

The Andalucian University Libraries concluded that if they wished to stay current with information technologies, if they wished to continue implementing improved services, and if they wished to do so within their budg- 
ets, solid cooperation mechanisms would have to be established.

In March 1998 the Andalucian vice-principals of research requested the directors of the Andalucian university libraries to analyze possible cooperative activities among the university libraries of the community.

Two goals were set in this meeting:

- The analysis of library automation products currently on the market.

- The analysis of the current individual management systems within the Andalucian libraries (which, though automation varied within them, were each considered to be outdated) and the potential for sharing resources with the present systems, which is difficult because currently available systems may not be compatible with Z39.50.

The object of this analysis is to define essential requirements so the new systems to be implemented facilitate possible cooperative actions. This possible integration will not be simple: the University Pablo de Olavide, recently created, is planning to purchase its own system; the universities of Seville, Granada, and Córdoba are using Dobis-Libis; and the universities of Cádiz and Málaga are using Libertas and are preparing to update to Innopac.

The Andalucian university libraries have studied some of the systems that the Spanish market offers: Abys (Baratz, Document Systems), Amicus (Elias), Innopac (SLS), Sabini (Sabini Library Automation) and Unicorn (Sirsi). They are preparing a catalog of electronic information resources available in the Andalucian university libraries to know which resources are available and preferred by different universities.

The Andalucian University Libraries Consortium is in an early stage; while its organizational structure and functions are defined, its tasks are still being elaborated. The Delegate Commission of the Vice-principals of Research of the Andalucian Universities is responsible for this work. The commission is presided over by the viceprincipal of the University of Seville and formed by the directors of the Andalucian libraries and the juridical consultant of the University of Córdoba.

The commision will produce a working paper that outlines the main facets of the organization, based on the following general principles:

- To add value to the computer net of research

- To favor the use of technologies that contribute to the improvement of the production times and the designing of efficient processes

- To apply scale economies:

- in the purchase of products and services

- in repetitive tasks and activities
- To favor the use of information resources

- among the members of the Andalusian universities and the society in general

In order for the project to succeed, the following conditions must exist:

- A homogeneous situation among the libraries in terms of regulations and technical instruments used in the description of materials, data format, and information interchange format;

- The Andalucian universities are connected with high speed optic fiber lines (32 MB);

- The administrative framework is clearly defined; and

- The responsible members of the Andalusian university libraries are convinced that cooperation will improve substantially the quality of the library services in each university.

Additionally, the following advantages must result:

- Decline or leveling of production expenses

- Economies of scale in the purchase of products such as computer systems, databases, and journal and electronic information subscriptions

- Shared technical support

- Shared training costs

- Shared information resources through interlibrary loan

\section{Conclusions}

The ultimate goal of cooperation is to join users and the documents and information they need; establishing relations among participant institutions is a means to that end. Consortia represent the possibility to test alternatives to the traditional automated library. They represent the potential to offer the best library services to a wider number of users with all the resources they possess.

Further than simple cooperation that unites efforts and resources, consortia represent the possibility to test innovative formulas of processes management and services organization from a regional perspective.

\section{References}

1. Miguel Duarte, "Evaluación del rendimiento aplicando sistemas de gestión de calidad, La Experiencia de la biblioteca de la Universidad de Cádiz" [Performance Assesment Implementing Total Quality Management Systems. The University Library of Cádiz Experience], in XV Jornadas de Gerencia Universitaria: Modelos de financiación, evaluación y mejora de la calidad de la gestión de los servicios [15th University Managers Meeting: Financing Models, Assesment and Quality Assurance 
of Services] (Cádiz, University Pr., 1997), 309-10; Marta Torres, "El impacto de las autopistas de la información para la comunidad académica y los bibliotecarios" [The Information Highway to Academic Community and Librarians], in Autopistas de la información: el reto del Siglo XXI (Madrid: Editorial Complutense, 1996), 37-55.

2. Víctor Castelo en la Mesa Redonda: Sueñan los informáticos con bibliotecas electrónicas. En Seminario sobre Consorcios de Bibliotecas [Dream the computerman with electronic libraries?] Table Ronde in Libraries Consortia Conference, Cádiz, University Press, 1999, 130; see also www.rediris.es, accessed Apr. 24, 2000.

3. M. Jiménez and Alice Keefer, "Library Automation in Spain," Program 26, no. 3 (1992): 225-37; Assumpciò Stivill, "Automation of University Libraries in Spain," Telephasa Seminar on Innovative Information Services and Information Handling (Tilburg, June 10-12, 1991); Rebiuns Statistical Annual offers data about catalog automation.

4. Luis Anglada and Margarita Taladriz, "Pasado, presente y futuro de las bibliotecas universitarias españolas" [Past, Present and Future of Spanish University Libraries] in IX Jornadas de Bibliotecas de Andalucia (Granada: Asociación Andaluza de Bibliotecarios, 1996), 108-31

5. L. Anglada, "Cooperació bibliotecària a Espanya [Library Cooperation in Spain]," Item 95, no. 16: 51-67.

6. See www.doc6.es/cdb, accessed Apr. 24, 2000.

7. See http://biblioteca.upv.es/bib/mecano, accessed Apr. 24,2000 .

8. See www.uned,es/bibliote/biblio/ruedo.htm and www.
baratz.cs/RUECA, accessed Apr. 24, 2000.

9. "The Library in the University: Report on the University Libraries in Spain, Produced by a Working Team Formed by University Librarians and Teachers" (Madrid: Ministry of General Culture of the Book and Libraries, 1985); "University Libraries: Recommendations about its Regulations, Conferences on University Libraries, 'Castillo Magalia,' Las Navas del Marqués," Avila, May 27-28, 1986 (Madrid: Library Coordination Centre, 1987).

10. Situación de las bibliotecas universitarias dependientes del MEC [Academic Libraries from Education Department State of Art] (Madrid: Universidad Complutense, Biblioteca, 1988); Estudio sobre normalización e informatización de las bibliotecas científicas españolas.-Fundesco, 1989 (no publicado).

11. Luis Anglada and Margarita Taladriz, 108.

12. See Consorcios de Bibliotecas [Consortia Libraries Conference], Maribel Gomez Campillejo, ed. (Cadiz: Cadiz Univ. Pr., 1999).

13. See www2.uji.es/rebiun, accessed Apr. 24, 2000.

14. For more information about CBUC, see www.cbuc.es, accessed Apr. 24, 2000

15. Marta Torres, Los Consorcios, forma de organización bibliotecaria en el S.XXI. Una aproximación desde la perspectiva española. In Consorcios de bibliotecas (Library Consortia Conference), 17-35.

16. Santiago Raya, "El Consorcio de Bibliotecas de Galicia [Galician Library Consortium]," in Consorcios de Bibliotecas [Library Consortia Conference], cit, 117-25. 